\title{
Is there a critical period for semantics?
}

\section{Roumyana Slabakova University of lowa}

Received August 2005; revised February 2006; accepted March 2006

\begin{abstract}
This article reviews recent research on the second language acquisition of meaning with a view of establishing whether there is a critical period for the acquisition of compositional semantics. It is claimed that the functional lexicon presents the most formidable challenge, while syntax and phrasal semantics pose less difficulty to learners. Findings from the neurofunctional imaging (PET, fMRI) and electrophysiology (ERPs) of L2 comprehension are reviewed and critically examined. Since it is argued that experimental tasks suggesting differential acquisition of L2 syntax and semantics are in need of linguistic refinement, further evidence is marshalled from behavioural studies of L2 acquisition of semantics to fill in the current gap in L2 comprehension modelling. The 15 studies reviewed here point to no apparent barrier to ultimate success in the acquisition of phrasal semantics.
\end{abstract}

\section{Introduction}

The well known contrast in attainment - universal success in the case of child first language (L1) acquisition, variable success in second language (L2) acquisition - has been amply documented (e.g. Johnson and Newport, 1989; Sorace, 1993). The contrast has also provided empirical evidence in favour of the hypothesis that L1 and L2 acquisition are profoundly different epistemological phenomena (Bley-Vroman's 1989 Fundamental Difference Hypothesis). This contrast in ultimate attainment has also frequently been related to the influence of age. The age variable examined in L2 acquisition studies is usually the age of first exposure to the L2 (or age of acquisition, AoA). Previous research (e.g.

Address for correspondence: Roumyana Slabakova, Department of Linguistics, University of Iowa, 557 English Philosophy Building, Iowa City, IA 52242, USA; email: Roumyana-slabakova@uiowa.edu 
Johnson and Newport, 1989) has suggested that AoA correlates negatively with native-like attainment and is apparently an important determinant factor of overall degree of success.

A reasonable explanation for the facts of L1 and L2 acquisition is given by the Critical Period Hypothesis (CPH) (Penfield and Roberts, 1959; Lenneberg, 1967). In its most theory-neutral formulation, it states that there is a limited developmental period during which it is possible to learn a new language - be it L1 or L2 - to normal, native-like levels. Once this window of opportunity has closed, however, the ability to acquire languages declines. The $\mathrm{CPH}$ rests on the assumption that agerelated effects are the result of maturational changes in brain structures that are used to learn and/or process language (Patkowski, 1980; Long, 1990). However, as Lenneberg himself acknowledges (Lenneberg, 1967: 176), it is not entirely obvious how the CPH relates to second language acquisition (L2A), since the L2 acquirers already have a native language and, in a way, the language centres in the brain have been activated in the opportune window. Thus, it is more appropriate to consider age-related effects in L2A, not a critical cut-off point, after which it becomes impossible to achieve native-like proficiency.

Another important idea that has gained a lot of support is that there are differential age-related effects for specific parts of grammatical competence. For example, Eubank and Gregg (1999) proposed that critical or sensitive periods affect various areas of linguistic knowledge differently (i.e. phonology, syntax, lexicon, etc.) and even subcomponents of these modules (e.g. lexical items, inflections, syntactic effects of abstract features). Lee and Schachter (1997) suggested that principles of universal grammer or UG (e.g. binding, subjacency) and parameters have different age-related cut-off points for successful triggering and acquisition (however, compare Coppieters, 1987; Birdsong, 1992). Proposals of this type can be united under the label Multiple CPH. In recent years, efforts have turned to isolating precisely which linguistic modules, submodules, features, or interface areas are affected, how, and why.

For example, Beck (1998) proposes a kind of maturationally-determined localized impairment specifically affecting the feature strength of functional categories. Another example is Hawkins and Chan's (1997) Failed Formal Features Hypothesis (FFFH) and its updated 
version (Hawkins, 2005; Hawkins and Hattori, this issue), which claims that uninterpretable features not selected from the UG inventory of features during the critical period disappear. ${ }^{1}$ The result is that L2 learners may use the morphology of the L2 with the feature specifications of their L1.

Sorace $(2000$; 2003) advances another hypothesis: Aspects of grammar that require the integration of syntactic knowledge with other types of information (e.g. pragmatic, semantic, prosodic) are more problematic for L2 learners than properties that require only syntactic knowledge. These latter properties may present residual difficulties even at the near-native level. In other words, the vulnerability resides at the syntax-semantics or the syntax-pragmatics interface (see Sorace and Filiaci, this issue).

The present article continues this vein of research by promoting the positive side of the argument (in terms of possibility of acquisition). I seek to demonstrate not what parts of the grammar are subject to agerelated effects but what is not subject to such effects. It is a very common assumption - articulated in, for example, Paradis (2004: 119) (but see also Samuels, 2000; Jackendoff, 2002) - that the language modules are phonology, morphosyntax and semantics. I refine the Multiple CPH by arguing that 'morphosyntax' is not a monolithic module in terms of processing, and should be divided into morphophonology and syntax, with quite different neural pathways. Semantics should also be viewed as comprising two types of linguistic operations on two levels: lexical semantics and phrasal semantics (Jackendoff, 2002). Support for this claim will come from experimental evidence that functional morphology vs. syntactic effects (movement, word order) are differentially affected in the behaviour of L2 learners, and from a re-interpretation of neurolinguistic studies of L2 comprehension. Thus, when we are told that 'syntax' is processed differently from 'semantics', what we are actually seeing is inflectional morphology encoded in the functional lexicon being treated differently from a universal process of semantic composition, which

${ }^{1}$ Features that make an essential contribution to meaning (e.g. plural, human or perfective) are interpretable, whereas those that are purely grammatical and only relevant to morphosyntax (e.g. case or agreement) are uninterpretable. 
comes to learners 'for free'. Furthermore, I look at acquisition of phrasal semantics, which, similar to the acquisition of the more subtle syntactic properties that come from UG, does not present insurmountable difficulty to the L2 learner. Behavioural studies of learners of all levels of proficiency are reviewed. Based on their success in acquiring interpretive properties, I argue that there is No Critical Period for (phrasal) semantics.

\section{The architecture of the language faculty}

The Minimalist research program (Chomsky, 2000; 2001; 2004) maintains the traditional characterization of language, since Aristotle at least, as a system that links sound and meaning. Thus, the expressions generated by a language must satisfy two interface conditions: those imposed by the articulatory-perceptual (AP) system and by the conceptual-intentional (CI) system. The language faculty is considered the optimal realization of the interface conditions.

Chomsky defends the idea that there should be only one level of computation, that between Numeration and Spell-Out, where Merge and Agree will apply, thus disposing of LF (logical form) and PF (phonetic form) as levels of computation. After the point of Spell-Out, there are only the AP and the CI interfaces. ${ }^{2}$ They provide the morphosyntactic information needed to linearize the linguistic signs and produce a sentence, as well as assign a semantic interpretation to that sentence.

Two types of feature are relevant to the syntax-semantics interface: interpretable and uninterpretable ones. Interpretable (semantic) features are legible at the interface and contribute to the interpretation, so they cannot be eliminated. Uninterpretable, or formal features, on the other hand, should be eliminated before Spell-Out, since they do not contribute to meaning. According to Chomsky $(2001 ; 2004)$, only interpretable features are encoded in the lexicon, while uninterpretable ones acquire their values, or are valued, and then deleted, in the course of the derivation. The set of functional categories constitutes a sub-module of syntax, namely, the Functional Lexicon (FL). Each functional category is associated with a lexical item, or items, specified for the relevant interpretable features. 
The Minimalist approach is challenged by Jackendoff (2002), who argues that the Chomskian picture of the language faculty is unfairly skewed towards syntax, in the sense that only syntax is the generative component of the grammar, while phonology and semantics are relegated to the interfaces. A further criticism is that the Minimalist framework does not make clear exactly what happens at the interfaces. In order to make linguistic theory more compatible with findings from neurolinguistics and psycholinguistics, Jackendoff proposes that all three modules of the grammar - phonology, syntax and semantics - are generative in the sense that they can generate structure by compositionally 'unifying' units dedicated to the particular level.

Another innovative feature of Jackendoff's framework is his treatment of the lexicon. For him, a lexical item is "a small-scale three-way interface rule" (p. 131): it lists a chunk of syntax, a chunk of phonology and a chunk of semantics as in (1). Inflectional morphology, idioms, as well as small phrasal trees with empty nodes, find themselves listed in this interface lexicon.

1)

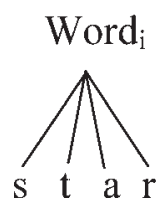

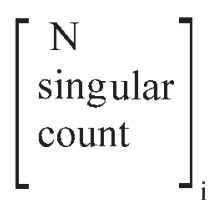

[object TYPE: STAR]i

An important insight of this proposal is that meaning has its own combinatorial structure and is not simply "read off the syntax", as the syntactocentric Minimalist program would have it.

The 64000 dollar question for L2 researchers is, of course, how much of Jackendoff's semantic/conceptual structure is universal and how much of it must be learned. He is very careful to answer this question:

it is clear that all these aspects of phrasal meaning are available in all the languages of the world ... languages differ in their syntactic strategies for expressing phrasal semantics; but the organization of what is to be expressed seems universal. The elements of the descriptive, referential, and information structure tiers seem the same across languages, and the principles of combination, especially on the descriptive tier, seem universally available. At least on preliminary reflection, the possibility of learning any of this would seem severely limited by the poverty of the stimulus. Thus I find it plausible that the basic architecture of conceptual structure is innate. (Jackendoff, 2002: 417)

Thus linguistic semantics is the study of the interface between conceptual form and linguistic form. It is the study of that part of our thoughts which can be expressed or invoked by language. 
What hosts most of the language variation in meaning, then, is the syntax-semantics interface. ${ }^{3}$ While the content of meaning is the same, different linguistic forms map different natural groupings of meanings. In this respect, Jackendoff and Chomsky converge. They relegate meaning differences between languages to the syntax-semantics interface, or LF. $^{4}$ I will assume this theoretical position and use it later on to explain different findings in the behavioural literature on L2A.

Another assumption that I will adopt from Jackendoff (2002) is the notion of the lexical item as interfacing between all three modules of structure; as being composed of syntactic, phonological and semantic features. There are "defective" lexical items like case endings (e.g. Nominative, Accusative, Genitive) in German, which comprise a chunk of phonology and a chunk of syntax, but have no semantics. On the other hand, the causative morpheme in English (as in I broke-CAUSE the vase) has semantics and syntax but no phonology. Since all lexical items have "their feet on three linguistic levels", it is potentially possible for knowledge of these three sides to be differentiated, or be acquired at different times. Form-meaning differentiations are well known in the L2A of functional words and morphemes. The threepronged view of lexical items can adequately account for such findings.

Although open-class words (notional lexical items) and closed-class words and morphemes (the FL) have in common their being "three-way interface rules", they differ essentially in the types of meanings they can encode. Current generative linguistic theory argues that not only overt syntactic properties but also properties computable at the syntaxsemantics interface depend crucially on features encoded in the FL. For example, overt vs. covert $w h$-movement is explained by a combination of a universal requirement on interpretation and a parameterized property. In order for sentences containing $w h$-words to be interpreted as questions, these words need to take (high) scope position at the interface, that is, they need to be in the $\mathrm{CP}$ projection. This is a universal requirement. The visible vs. invisible movement has been taken to depend parametrically

${ }^{3}$ Prosody (e.g. question intonation in languages) also contributes to the meaning calculation. This is reflected in Jackendoff's (2002: 125) model by a special phonological structure-conceptual structure interface.

${ }^{4}$ However, Jackendoff envisages much more work being done at the interface, thereby relieving syntax of much of its complexity. 
on features encoded in the $w h$-words in a language. Thus, interpretive properties encoded at the syntax-semantics interface like wh-movement do not seem to be qualitatively different from purely syntactic properties like verb movement which do not give rise to interpretive differences between languages. That is, in verb-raising languages the verb does not move for interpretive reasons. In $w h$-movement, the $w h$-word does move for scope-taking reasons. However, both movements are triggered by properties encoded in the FL. In principle, then, we should expect a similar pattern of processing and similar behavioural patterns of acquisition for abstract, subtle syntactic and semantic properties.

In sum, we will assume a universal and generative semantic/conceptual module, lexical items as interfaces between the three modules, and an open- vs. closed-class lexical item distinction, where closed-class FL items trigger movement for interpretive or purely semantic reasons.

\section{Some pointers from neurolinguistics}

Why would we find credible the proposal that all three modules of language are generative? As mentioned in the introduction, there seems to be a growing consensus that language is represented as an integrated system of neurofunctional modules, at least phonetics/phonology, morphosyntax and semantics being such modules (see, amongst others, Samuels, 2000; Jackendoff, 2002; Paradis, 2004). These modules may be represented in dedicated networks of neurons involving interconnected areas. Since in this article we are most interested in the syntactic and the semantic modules, we now turn our attention to these two. I follow Paradis (2004) in accepting that neurofunctional modules are isolable (selectively susceptible to lesions and inhibition) and computationally largely autonomous (each module has access only to the output of another, but their internal processes do not interact (Paradis, 2004: 119).

Neuroimaging studies ${ }^{5}$ investigating semantic processes at the sentence comprehension level argue that the left inferior frontal gyrus, the

\footnotetext{
${ }^{5}$ Functional neuroimaging, and most notably functional magnetic resonance imaging (fMRI), has seen an explosion of research papers in the past decade. This technique can provide a coarse measure of activity by monitoring the blood flow at different locations of the human brain while people are performing various cognitive tasks. For a recent review of this technique in the study of bilingualism, see Abutalebi et al., 2001, Paradis, 2004.
} 
right superior temporal gyrus and the left middle temporal gyrus, as well as the left posterior temporal region, are activated when we process meaning. When semantic memory resources are involved in a comprehension task (e.g. comparing two sentences for meaning), frontal cortex is recruited (Friederici, 2002). On the other hand, syntactic processes involve inferior frontal cortex and the anterior portion of the temporal cortex. Neurofunctional imaging is not sufficiently detailed at present to give us a picture differentiating processes down to groups of neurons, so there is some overlap between areas subserving syntactic and semantic processes (for a critique of neuroimaging studies, see Paradis, 2004). Furthermore, the areas used to comprehend syntax and semantics are not uniquely dedicated to these tasks. For example, parts of Broca's area are activated in the processing of music (Maess et al., 2001), perception of the rhythm of motion (Schubotz and von Crammon, 2001) and imagery of motion (Binkofski et al., 2000).

Electrophysiological studies of the time course of language processing using Event-related Potentials (ERPs) ${ }^{6}$ have contributed substantially to upholding syntax-semantics functional modularity. The main effect of a semantic incongruity in a sentence is a negative wave with an onset at about $250 \mathrm{~ms}$ after the critical word and a peak of $400 \mathrm{~ms}$, the so-called N400 (Kutas and Hilliard, 1980). The N400 was originally discovered to be sensitive to semantic integration of a word into a sentence:

2) He spread his warm bread with ...

socks

SEMANTICALLY INCONGRUENT

3) He spread his warm bread with...

butter SEMANTICALLY CONGRUENT

It was later found by Hagoort and Brown (1994) that expectancy (as in a cloze probability that the supplied word is the expected word) plays a role for the N400 effect. The amplitude of this effect is most sensitive to the semantic relations between individual words, or between word and sentential context, word and discourse context or, generally speaking, with the processing costs of integrating the meaning of a word into the semantic representation that is built up on the basis of the preceding

${ }^{6}$ ERPs are becoming an increasingly important tool in the assessment of cognitive development and processing. ERPs are a measure of the brain's response to particular events, such as the presentation of a sound or picture, and they form a small portion of the electroencephalogram (EEG). The ERPs are extracted by averaging the EEG over many presentations of the sound or picture. These averaged waveforms consist of peaks and valleys that have been shown to be associated with perceptual and cognitive processing of the stimuli. For a review of this technique in studying L2 processing, see Müller, 2005. 
language input (Osterhout and Holcomb, 1992; Brown and Hagoort, 1993). We return to a discussion of this effect below.

Syntactic processes are correlated with two other qualitatively different processes: an early left-anterior negativity, known as LAN, and a late centro-parietal positivity labelled P600. A very early LAN, or ELAN, correlates with word category errors (Friederici, 1995, 2002; Friederici et al., 1996). LANs within a 300-500 ms range correspond to number, gender, case and tense mismatches (Münte et al., 1993; Friederici, 2002). LAN effects have also been linked to tasks taxing verbal working memory (Kluender and Kutas, 1993). The second syntactic ERP effect, the P600, emerges if a syntactic requirement like agreement is violated, or in garden-path sentences where backtracking and reconsidering the whole tree is required (Osterhout and Holcomb, 1992; Hagoort et al., 1993; Kaan et al., 2000). An argument for the independence of this effect from potentially confounding semantic factors is that the P600 also occurs with semantic garbage like the examples in (4), where one sentence has an agreement violation but the other does not (Hagoort and Brown, 1994):

4) a. The boiled watering can smokes the telephone in the cat. b. The boiled watering can smoke the telephone in the cat.

P600 effects have been reported for phrase structure violations (Osterhout and Holcomb 1992; Hagoort et al., 1993), subcategorization violations (Ainsworth-Darnell et al. 1998), subjacency (McKinnon and Osterhout, 1996) and the Empty Category Principle (McKinnon and Osterhout, 1996).

In summary, the three ERP effects described above for native speakers vary in latency, polarity and topographic distribution. The N400 is qualitatively dissociated from the LAN and the P600, thereby suggesting that syntactic and semantic processing of language are modular indeed.

If, as we have seen, neural processes for syntax and semantics are functionally specialized, it is conceivable, then, that they should adapt differently to maturation and experience. It is well-established in the literature now that delays in language experience do not affect language processes uniformly. We turn to the neurophysiology of L2A (for recent reviews, see Abutalebi et al., 2001; Paradis, 2004: Chapter 6; Müller, 
2005). As Paradis cautions, the results of the existing studies are often contradictory and they should be compared extremely carefully. Still, some consensus emerges. Most studies find that early bilinguals activate the same cortical areas when processing their native and their second language (Kim et al., 1997; Chee et al., 1999; 2001; Urbanik et al., 2001). When late bilinguals are tested, then proficiency level becomes the important variable: less proficient L2ers are reported to have different patterns of activation (Perani et al., 1996; Dehaene et al., 1997; Kim et al., 1997; Urbanik et al., 2001) while more proficient bilinguals activate the same areas as in their L1 (Perani et al., 1998; Illes et al., 1999).

Three studies are of particular importance for us at this point, because they used a similar task, listening to stories in the L1 and the L2 while being scanned: Perani et al., 1996; 1998; Dehaene et al., 1997. Dehaene and colleagues scanned low proficiency French learners of English and found considerable individual variation among the cerebral substrates engaged. Perani et al. (1998) controlled for the age and proficiency factors, studying two groups of highly proficient learners: one group started L2A later than the other (after 10 as compared to after 4 years of age). Among these proficient learners, age of acquisition was not a significant factor predicting neurofunctional differences. The authors concluded that there is evidence of considerable plasticity in the network that mediates language comprehension.

The electrophysiological studies on L2 learners also support this claim of higher neural plasticity for semantics as opposed to morphosyntax. Weber-Fox and Neville (1996) is the first study to point to differential sensitivity of syntactic processing to AoA effects. According to them, syntactic processing is more dependent on AoA (affected by an AoA of 1-3 years of age) than semantic processing (affected by an AoA of more than 11 years). Hahne (2001) and Hahne and Friederici (2001) found that semantic integration is processed similarly by natives and L2 learners (although the N400 effect had a lower amplitude and was somewhat delayed), while phrase structure violations are not. The same pattern emerged in the neuroimaging studies. While processing semantics, L1 and L2 speakers do not differ qualitatively. While processing morphosyntax, however, proficiency immediately becomes a factor (Wartenburger et al., 2003). The development of automatic implicit processing seems possible, but is influenced by the complexity of the 


\section{Is there a critical period for semantics?}

system to be acquired. In a clever little study, Friederici (2002) explicitly argues against the $\mathrm{CPH}$ using acquisition of an artificial language. They showed that if a small grammatical system is to be acquired, L2 learners exhibit exactly the same event-related brain potential components that are related to early automatic processing and to late-controlled syntactic processing in native speakers. Pointing in the same direction is another study, by Weber-Fox and Neville (2001), who found age effects in processing closed-class words (inflectional morphology) only, but not open-class words. They argued that neural subsystems responsible for grammatical processing appear to be more sensitive to the age of L2 immersion.

In summary, recent evidence (Perani et al., 1998; Chee et al., 1999; 2001; Wartenburger et al., 2003) points to the conclusion that both AoA and proficiency are critical determinants of cerebral organization of language processing in adult L2 learners. However, AoA is a more important determinant for syntactic than for semantic processing.

\section{What are the neurolinguistic studies of bilinguals really testing?}

There is recent debate in the cognitive science literature on the usefulness of fMRI and ERPs as a new tool for studying human cognition (two companion articles are Henson, 2006; Poldrack, 2006; see references therein; for arguments from the viewpoint of neurolinguistics, see also Paradis, 2004; Vaid and Hull, 2002).

Although functional neuroimaging techniques are an exciting new tool of cognitive science, haemodynamic and electrophysiological changes in the brain are not direct windows into cognitive processes. Scientists must first have determined the mental representations that speakers establish when presented with linguistic stimuli, and then the cognitive processes used to invoke these representations. The former are accessed by linguistic judgements, the latter by behavioural psycholinguistic tasks. In order to establish the correct and detailed ontology of cognitive processes in linguistics (what task engages what cognitive process and by what mechanism), results from behavioural studies should necessarily precede and complement neurolinguistic studies. As things stand right now, the linguistic tasks used to study 
comprehension (e.g. listening to stories) probably engage too many disparate cognitive processes to be taken as an adequate reflection of semantic processing effects in the brain.

Let us take a closer look at what is considered a syntactic and a semantic violation, at least in the studies investigating bilinguals. All of the studies reviewed briefly in Section 4 bracket together, under the label 'semantic violation', sentences that violate constraints on matching semantic features as well as sentences in which one critical word cannot be easily integrated in the context, or is unexpected. As an example of a feature mismatch, or a presupposition violation, take the classical He spread his warm bread with socks. The semantic features of bread (edible stuff) must match those of its modifier, which in the case of socks is violated. On the other hand, Hagoort and Brown (1994) show that subtle differences in the cloze probability of a word in a sentence, such as between mouth and pocket in the sentence Jenny put the sweet in her mouth/pocket after the lesson can also modulate the N400 amplitude, although no presupposition is violated. Thus, the N400 effect is sensitive not only to semantic violations, but also to integration of words into a preceding discourse context and to cloze probability expectations. This situation is an apt illustration of the frequent (and disastrous) lack of behavioural data in interpreting neuroimaging and electrophysiological findings. One experimental task may produce the same ERP effect with different stimuli, but until we know exactly what cognitive processes are triggered by this task and the stimuli, the ERP findings will be of limited consequence.

This observation is reinforced by a recent study of N400 effects. Hagoort et al. (2004) recorded magnetic fields while participants read three types of sentences as in (5): a true sentence, a world knowledge violation and a 'semantic violation'.

5) a. The Dutch trains are yellow and very crowded.

b. The Dutch trains are white and very crowded.

c. The Dutch trains are sour and very crowded.

TRUE

WORLD KNOWLEDGE VIOLATION SEMANTIC VIOLATION

No difference was found in the timeline and the way Dutch natives process the world knowledge violation (5b) and the semantic violation (5c). Both sentences evoke an N400 as compared to the true sentence. The authors conclude that the same brain area (left inferior prefrontal cortex) is involved in the integration of both meaning and world knowledge 
and that "it does not take longer to discover that a sentence is untrue than to detect that it is semantically anomalous" (p. 440). But heeding the caution that the same first author advised 10 years earlier, we cannot know whether those results are a reflection of the processing of a semantic violation, world knowledge violation or simply an unexpected word effect. Combining these findings with behavioural data from semantic and pragmatic processing would increase their reliability.

What kind of linguistic stimulus would allow us to study authentic semantic processing, apart from the presupposition violations mentioned above? For one, semantically ambiguous sentences like the classical quantifier ambiguities as in (6) induce semantic calculations over and above the strictly compositional semantics, since they may involve Quantifier Raising (May, 1985).

6) Everyone loves someone.

a. There is one person $x$ that is loved by everyone.

b. Everyone has tender feelings for someone or other, making pairs of 'lover' and 'loved'.

Such sentences, involving two quantifiers, or a $w h$-word and a quantifier, are studied by Dekydtspotter and Outcalt, 2005; Marsden, 2003; 2004.

Another option would be to compare sentences that exhibit semantic coercion as in (7) (Jackendoff, 1996) and to compare them with sentences where the verb does not need coercion as in (8). ${ }^{7}$ The adverbial until dawn must combine with an atelic predicate, providing a telos (endpoint) for it. In (7), however, the verb flash, an achievement, is inherently telic since it encodes an instantaneous event. The adverbial, then, coerces the verb meaning into a series of repetitive events, until dawn. The atelic verb sing in (8), on the other hand, does not employ the semantic operation of aspectual coercion but simple composition.

7) The light flashed until dawn.

8) He sang until dawn.

TELIC, COERCED INTO ATELIC TRULY ATELIC

Semantic structure is violated, also, when we combine an inherently telic predicate (the achievement recognize) with for $X$ time adverbial,

\footnotetext{
${ }^{7}$ Some authors would claim that this process involves aspectual coercion forced by context, in a way, a contribution of the discourse representation that starts after the compositional interpretation has been given (de Swart, 1998). The border between semantics and pragmatics is fuzzy, and very much an empirical question still. I am grateful to an anonymous reviewer for putting me straight on this and other semantic issues.
} 
which is felicitous with atelic predicates. We expect a similar sort of effect as in (7) above. The predicate recognize, however, resists aspectual coercion, since we cannot recognize the same individual many times over. Therefore a semantic incompatibility arises, marked with \#.

9) \# John recognized the man in the picture for an hour.

To my knowledge, the inquiry into early vs. late bilingualism is still awaiting neurolinguistic studies using this type of linguistic stimuli.

Let us turn now to an examination of the "syntactic" violations tested in the neurofunctional studies on bilinguals. The most common type of stimulus sentence ${ }^{8}$ comprises syntactic violations involving incorrect agreement in number, gender or case (e.g. Wartenburger et al., 2003: 168). Recall that the language faculty architecture we reviewed in Section 2 posits different status for lexical entries in the functional lexicon vs. syntactic operations like movement of constituents. We can view this as the difference between inflectional morphology and syntax proper, a distinction well known to linguists. Now, lexical entries, be they referential or functional, are arguably stored in declarative memory (also known as explicit memory; see Paradis, 1994; 2004; Ullman, 2001; 2004) while other syntactic processes are subsumed by procedural memory (an implicit process). It is very likely, then, that these two qualitatively different routes (the processing of functional morphology and of syntax) are differentially affected by AoA in second language acquisition. In a way, that can distinguish between the phonological features and the syntactic features encoded in inflectional morphemes. In fact, a recent survey of syntactic processing in native speakers, by Kaan and Swaab (2002), explicitly argues for syntactic processing recruiting multiple brain areas.

we propose that the different parts of the network are recruited for different aspects of syntactic processing. The middle and superior temporal lobes might be involved in lexical processing and activating the syntactic, semantic and phonological information associated with the incoming words; the anterior temporal lobe might be involved in combining the activated information or encoding the information for later use; and

\footnotetext{
${ }^{8}$ Weber-Fox and Neville (1996) is a notable exception to this trend. The researchers tested truly syntactic violations: phrase structure violations (e.g. *The scientist criticized Max's of proof the theorem), specificity constraint violations (e.g., *What did the scientist criticize Max's proof of?), and subjacency violations (e.g. *What was a proof of criticized by the scientist?). However, they completely disregard properties of the native language, therefore not discussing how Chinese, the L1 of their learners, works with respect to these violations.
} 
Broca's area might be involved in storing non-integrated material when processing load increases. (Kaan and Swaab, 2002: 355)

The bilingual imaging literature, however, does not make these finergrained distinctions between lexicon and syntax just yet. Until bilinguals are scanned while processing functional morphology violations as well as syntactic violations, the claims of syntax and semantics being differentially affected by AoA should be suspended. ${ }^{9}$

In this section, I discussed some problems with the test items in neurolinguistic studies of bilingual processing. I argued that L2 imaging of true semantic violations and ambiguity is still awaiting research. I also suggested that "syntactic processing" is by no means monolithic, and has to distinguish between the processing of closed-class words and inflectional morphology, on the one hand, and syntax proper, on the other. In the next section, I look at the role of functional morphology in more detail.

\section{More on the role of inflectional morphology}

White (2003: Chapter 6) describes two views of the morphology-syntax connection, which she labels morphology-before-syntax and syntaxbefore-morphology (p. 182-84). On the morphology-before-syntax view (Radford, 1990; Clahsen et al., 1993/94), lexical acquisition of functional morphology actually drives the acquisition of functional categories. Until the morphology is in place, learners lack knowledge of functional categories. This view assumes that rich agreement morphology is causally related to overt syntactic movement (not an uncontroversial position; see Sprouse, 1998; Bobaljik, 2002). The syntax-before-morphology view, on the other hand, assumes that abstract syntactic features encoded in the

\footnotetext{
${ }^{9}$ In fact, a very recent review of ERP studies on bilinguals, Müller (2005) comes to a similar conclusion. After summarizing the findings of several studies, the author notes that the two syntactic effects are differently affected by AoA. The LAN or ELAN indicative of a functional morphology violation is affected by AoA (Weber-Fox and Neville, 1996; Hahne, 2001; Hahne and Friederici, 2001). The P600, on the other hand, subserving phrasal and sentential syntactic processing, was strikingly similar to native speakers' in the most proficient learners, thereby indicating that complex syntactic processing might involve the same neural pathways as in natives (Weber-Fox and Neville, 1996; Hahne, 2001; Sabourin 2003). However, the author does not relate the two ERP effects to functional morphology and the abstract syntactic processes triggered by that morphology. More informed attention to testing materials is needed, of course, before solid conclusions are drawn.
} 
morphology, those that have an effect on sentence syntax and semantics, should be treated as distinct from the surface morphological forms (that is, their phonological features) (Lardiere, 2000).

On the latter view, L2 learners who do not have perfect performance on the inflectional morphology can still have engaged the functional categories related to that morphology and have the abstract syntactic features represented in their interlanguage grammar. Evidence comes from several studies of child and adult L2 production (Haznedar and Schwartz, 1997; Lardiere, 1998a; 1998b; Haznedar, 2001; Ionin and Wexler 2002). What is especially striking in the data is the clear dissociation between the incidence of verbal inflection (ranging between $46.5 \%$ and $4.5 \%$ ) and the various syntactic phenomena related to it, like overt subjects, case-marking on subjects and verb placement (above $98 \%$ accuracy).

In sum, inflectional morphology and closed-class words as entries in the FL may be stored by declarative (explicit) memory, enter the interlanguage grammar incrementally and present difficulty to learners. At the same time, they are responsible for syntactic effects like word order as well as interpretation. Our main goal in this article, then, is to distinguish between the two processes: acquisition of the FL and acquisition of semantic interpretations, and argue that L2 difficulties stem from the FL and not from the application of universal semantic principles. In this respect, my argument is similar to the syntax-before-morphology view of White (2003) and can be labelled "semantics-before-morphology". In the next section, we see whether the available empirical evidence supports a stronger or a weaker version of semantics-before-morphology.

\section{Evidence from behavioural studies of L2A}

The 15 studies summarized in this section - three of them in more detail - attest to the recent explosion of interest in studying interlanguage knowledge at the syntax-semantics interface. There are two sources of L1-L2 mismatches in these studies (and more generally). One type of learning task is such that the L2 syntax presents difficulty for the learner, but the semantics is straightforwardly read off the syntax, once a correct syntactic representation is established. The other mismatch can be at the interface itself: the syntax does not present any 


\section{Is there a critical period for semantics?}

difficulty, and can even be superficially identical in the L1 and the L2, but the semantics offers different interpretations. We shall see examples of both types of mismatches in this section.

\section{Dekydtspotter and Sprouse (2001)}

Laurent Dekydtspotter and Rex Sprouse (henceforth D\&S) are the pioneers of the acquisition of semantics line of research. They initiated a research program aimed at investigating the L2 acquisition of POS effects at the syntax-semantics interface in English-French interlanguage. They looked at the process vs. result interpretations of double genitives (Dekydtspotter et al., 1997) at single-event vs. multiple-event interpretations of quantifiers in adverbial position (Dekydtspotter et al., 1999/2000); and at wide-scope vs. narrow-scope interpretation of restrictions on cardinality interrogative quantifiers (Dekydtspotter et al., 2001). In this article, I summarize their argument from an experiment on tense-dependent interpretations, D\&S (2001). The semantic knowledge to be acquired involves the speech-time vs. present time construal of adjectival restrictions of quantifiers. Consider the data in (10).

$\begin{array}{rlllll}\text { (10) a. Qui } & \text { de } & \text { célèbre } & \text { fumait } & \text { au bistro } & \text { dans les années 60? } \\ \text { who } & \text { of } & \text { famous } & \text { smoked } & \text { in the bar } & \text { in the 60s? } \\ \text { b. Qui } & \text { fumait } & \text { de } & \text { célèbre } & \text { au bistro } & \text { dans les années 60? } \\ \text { who } & \text { smoked } & \text { of } & \text { famous } & \text { in the bar } & \text { in the 60s? }\end{array}$

'Which famous person smoked in bars in the 60s?'

A possible answer to the question in (10a) may involve a present or a past celebrity. On the other hand, it is impossible to answer the discontinuous interrogative constituent as in (10b) with a present celebrity. Only someone who was a celebrity in the past is the appropriate answer.

The linguistic properties supporting these interpretations combine language-specific movement for checking of a $w h$-feature, the possibility of left-branch extraction (again, language-specific) and a universal semantic-computational mechanism. When a wh-phrase (qui) moves to Spec, CP to check a strong $w h$-feature (pied-piping the rest of the phrase with it) it can optionally take its adjectival restrictions (de célèbre) along for the ride, resulting in the structures in (11a) and (11b); D\&S's (3) and (4). 


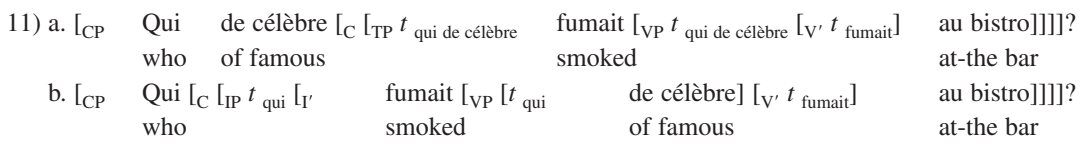

The relevant aspects of the expression qui de célèbre are interpreted at all the various steps in the derivation. More specifically, the analysis in (11a) allows de célèbre to be interpreted in CP, in TP, or in VP (assuming local movement). The past tense operator $\mathrm{P}$ is located in TP. Thus, the continuous interrogative constituent can be interpreted to pertain to either people who are famous at the time of the utterance (without tense restrictions), or to people who were famous at the time when the smoking in bars, the verbal predicate, was taking place. On the other hand, the discontinuous constituent in (11b) has the adjectival restriction in VP, under the scope of the past operator, hence one of the interpretations is missing. The habitual smoking event and the state of being famous must coincide temporally.

What kind of knowledge must an L2 learner have in order to be aware of both interpretations in the case of continuous wh-constituents but only one interpretation in the case of discontinuous ones? First, knowledge of overt $w h$-movement is required, but such knowledge can be transferred from the native language in English-French interlanguage. Second, knowledge that discontinuous interrogatives are allowed in French is necessary. That property is not taught in French classrooms (D\&S, 2001: 7). Third and most importantly, what D\&S label "the universal deductive procedure" is indispensable for reaching the interpretive knowledge.

The researchers tested 47 intermediate and 11 advanced English-native learners of French. Two control groups were tested as well. ${ }^{10}$ Participants read a paragraph-length context in English matched with a test sentence in French, then had to answer whether that sentence was the correct answer to the question. Test sentences in the form of question and answer sequences were organized in quadruples, as exemplified below:

12) Sample stimuli: Context for all 4 items in the quadruple:

Attitudes toward smoking have changed drastically since the 1960s. In the 1960s many people would go to bars and smoke every night. For example, Herman the Hermit was

\footnotetext{
${ }^{10}$ One control group was made up of 30 native French speakers, the other of 47 English-speaking individuals with no exposure to French. The purpose was to see how the interlanguage group would have performed on the experimental task if they had judged the test sentences based on their English intuitions.
} 
a famous rock star in those days and was often seen at bars smoking with Linda Tripp, who was then totally unknown. How times have changed! Now it is Linda Tripp who is famous, and neither of them smokes any more!

- Continuous interrogative with past time answer:

Mme Goyette: Qui de célèbre fumait - dans le bistro - pendant les années 60? Élève:

Herman the Hermit

- Continuous interrogative with speech time answer:

Mme Goyette: Qui de célèbre fumait - dans le bistro - pendant les années 60?

Élève:

Linda Tripp

- Discontinuous interrogative with past time answer:

Mme Goyette: Qui fumait de célèbre - dans le bistro - pendant les années 60?

Élève:

Herman the Hermit

- Discontinuous interrogative with speech time answer:

Mme Goyette: Qui fumait de célèbre - dans le bistro - pendant les années 60?

Élève:

Linda Tripp

Question for respondents on all items:

IS THIS A CORRECT ANSWER TO THE QUESTION?

The results are summarized in Table 1 (based on D\&S, 2001).

Past time construals are preferred across the board by natives and learners alike. Speech time construals are in bold with a checkmark after the available one and a star after the unavailable one. It is knowledge of the missing interpretation, the speech-time construal with discontinuous constituents, that is crucial in answering the research question of this study. Both learner groups show a statistically significant difference between the available and the unavailable interpretations; i.e. they reliably treat the two constructions differently. The argument would have been more convincing if the native speakers had exhibited more categorical knowledge of the property. As it is, French natives do not like speech time construals, and do not reliably distinguish between the two constructions $(t(29)=1.61, p=.119)$. However, what is important is the behaviour of the learners, who

Table 1 Percentage of acceptance of past time and speech time construals in continuous and discontinuous interrogatives

\begin{tabular}{|c|c|c|c|c|c|c|}
\hline \multirow[t]{2}{*}{ Construal } & \multicolumn{2}{|c|}{$\begin{array}{l}\text { Intermediate } \\
\quad(n=47)\end{array}$} & \multicolumn{2}{|c|}{$\begin{array}{l}\text { Advanced } \\
(n=11)\end{array}$} & \multicolumn{2}{|c|}{$\begin{array}{l}\text { Native French } \\
\quad(n=30)\end{array}$} \\
\hline & Past & Speech & Past & Speech & Past & Speech \\
\hline $\begin{array}{l}\text { Continuous } \\
\text { interrogatives }\end{array}$ & 90.7 & $41.2(\checkmark)$ & 79.6 & $46.6(\checkmark)$ & 88.8 & $12.5(\checkmark)$ \\
\hline $\begin{array}{l}\text { Discontinuous } \\
\text { interrogatives }\end{array}$ & 90.7 & $25.0(*)$ & 90.9 & $15.9(*)$ & 96.3 & $5.0(*)$ \\
\hline
\end{tabular}


successfully combine the properties related to the French functional lexicon: the availability of $w h$-movement and discontinuous interrogatives, with the universal meaning-calculating algorithm. Note that even not very proficient L2 learners - in this case learners with as little as three semesters of exposure to French - are capable of manifesting knowledge depending on this universal algorithm.

\section{Montrul and Slabakova (2002)}

In a series of studies (Montrul and Slabakova, 2002; 2003; Slabakova and Montrul, 2002; 2003) Montrul and Slabakova (henceforth M\&S) investigated acquisition of interpretive properties related to the aspectual functional projection AspP, in English-Spanish interlanguage. M\&S (2002) was a study specifically designed to probe the connection between acquisition of inflectional morphology and interpretations related to the aspectual tenses Preterite and Imperfect.

Spanish and English aspectual tenses encode different meanings. While the English past progressive tense signifies an ongoing event in the past, Spanish Imperfect can have both an ongoing and a habitual interpretation. The English simple past tense, on the other hand, has a one-time finished event interpretation and a habitual interpretation while the Spanish Preterite has only the former. The examples below illustrate this:

13) a. Guillermo robaba en la calle.

Guillermo rob-IMP in the street

HABITUAL

'Guillermo habitually robbed (people) in the street.'

b. Guillermo robó $\quad$ en la calle.
Guillermo rob-PRET in the street
'Guillermo robbed (someone) in the street.'

14) a. Felix robbed (people) in the street.

b. Felix robbed a person in the street.

ONE-TIME EVENT

In the diagrams in Figure 1, circles enclose meanings that are encoded by the same piece of inflectional morphology. In restructuring his or her grammar, the learner has to acquire the fact that it is the Imperfect morphology that encodes habituality in Spanish, and not the perfective Preterite morphology. Another acquisition task is noticing that the Imperfective ending is ambiguous between two interpretations, 

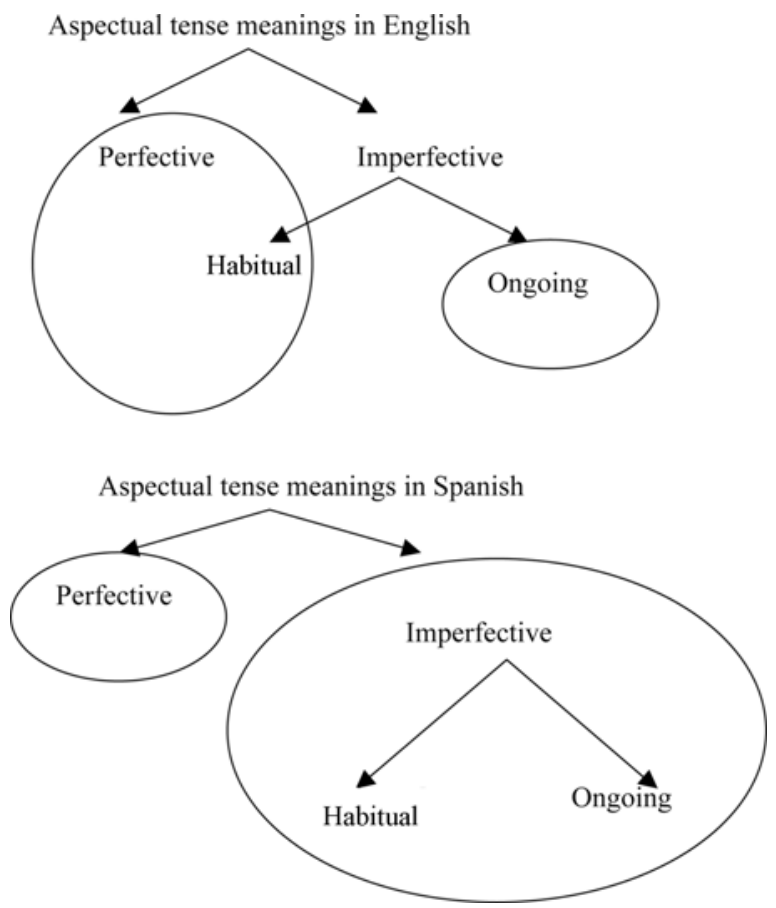

Figure 1 Aspectual tense meanings in English and Spanish

habitual and ongoing, while the Preterite ending only encodes the perfective meaning of a one-time finished event. This situation presents a mismatch between syntactic structure and conceptual structure. The pieces of inflectional morphology come from the functional lexicon. The functional projections (e.g. AspP) where features are checked are part of sentence syntax. The aspectual meanings (ongoing event, habitual event, one-time finished event) reside in conceptual structure. But different languages have different form-to-meaning mappings, which are calculated at the syntax-semantics interface.

M\&S (2002) tested 71 adult learners of Spanish, divided into Advanced and Intermediate learners. Based on a test of inflectional morphology of aspectual tenses, the Intermediate learners were further divided into a yesmorphology group and a no-morphology group. The main test instrument was a sentence conjunction judgement task, which specifically tested the semantic implications of the Preterite and Imperfect tenses. In this task, 
participants were presented with a list of sentences consisting of two coordinated clauses. Some of the combinations were logical while others were contradictory. Participants had to judge on a scale ranging from -2 (contradiction) to 2 (no contradiction) whether the two clauses made sense together. Following is an example with an accomplishment verb:

15) a. Joaquín corría (imperf) la carrera de fórmula 1 pero no participó.

'Joaquín was going to participate in the Formula One race but he didn't take part in it.'

$$
\begin{array}{lllll}
-2 & -1 & 0 & 1 & (2)
\end{array}
$$

b. Pedro corrió (pret) la maratón de Barcelona pero no participó. 'Pedro ran the Barcelona marathon but he didn't take part in it.'

-2 $\quad \begin{array}{llll}-1 & 0 & 1 & 2\end{array}$

Group results show that advanced and intermediate learners who scored above $80 \%$ accuracy with the morphology test appear to have acquired the semantic implications associated with Preterite and Imperfect tenses in Spanish. By contrast, those intermediate learners who did not control knowledge of the Preterite/Imperfect morphophonology were not yet sensitive to the semantic contrast between these tenses, especially with achievement and state predicates.

For individual participants, in order to establish whether there was a correlation between knowledge of morphology and knowledge of semantics with the three types of predicate tested (accomplishments, achievements and states), frequency distributions were calculated (see Table 2).

The authors interpreted these findings as suggesting that knowledge of morphology necessarily precedes knowledge of semantics in this aspectual domain, and that the acquisition of the semantic contrast may be a gradual development which eventually reaches complete nativelike knowledge in advanced proficiency learners. They explained the higher accuracy on the morphology with the context of acquisition (aspectual morphology endings are explicitly taught and drilled in language classrooms) and with the nature of the morphology test (recognition of the correct form in context, one out of only two choices).

Superficially, the findings of this study seem to flatly contradict the semantics-before-morphology view that I proposed at the end of Section V. However, it would be premature to abandon this view completely. First of all, the syntax-before-morphology view (including the 
Table 2 Distribution of learners according to acquisition of the morphology and semantics of aspectual tenses in Spanish (Yes $=$ have acquired, No $=$ have not acquired)

\begin{tabular}{|c|c|c|}
\hline & Yes morphology & No morphology \\
\hline \multicolumn{3}{|c|}{ Accomplishments $(p<0.0023$; unclear $n=5)$ : } \\
\hline Yes semantics & 21 & 2 \\
\hline No semantics & 21 & 22 \\
\hline \multicolumn{3}{|c|}{ Achievements $(p<0.0023$; unclear $n=4)$ : } \\
\hline Yes semantics & 20 & 1 \\
\hline No semantics & 21 & 25 \\
\hline \multicolumn{3}{|c|}{ States $(p<0.0001$; unclear $n=5)$ : } \\
\hline Yes semantics & 21 & 2 \\
\hline No semantics & 21 & 22 \\
\hline
\end{tabular}

Notes: Yes $=$ have acquired; No $=$ have not acquired. The unclear cases had 4 correct answers out of 7 in one tense and 5 out of 7 with the other. All other individual participants had 5 or more correct answers with both tenses, in order to be classified as having learned the semantics. The cut-off point for successful acquisition of the morphology was $80 \%$.

Missing Surface Inflection Hypothesis) is supported with robust evidence from production while the M\&S study reviewed here looks at recognition of inflectional morphology in comprehension, a much easier task. Second, even if a stronger version of semantics-before-morphology is not supported, a weaker version of similar theoretical import could be labelled The Bottleneck Hypothesis, which postulates that it is the functional morphology indeed that is the "tight spot" in the acquisition process flow. It is processed by declarative memory, has to be learned by rote, and its forms (or phonological features) present difficulty for L2 learners not only at beginning stages of acquisition but at later stages, too (Lardiere, 2005). It is a stumbling block in linguistic production but is also crucial in comprehension. After the figurative bottleneck, application of universal semantic principles continues to flow freely, and target interpretations are achieved.

\section{Slabakova (2006)}

Slabakova (2006) is a bidirectional study of a purportedly truly semantic parameter, the Bare Noun / Proper Name parameter (Longobardi, 2001). English and Italian bare plurals and mass nouns, subsumed under the common label Bare Nouns (BNs), which have identical syntactic form 
and distribution, differ in available interpretations. In English, BNs have two interpretations while their Italian equivalents have only one interpretation. Longobardi argues that this semantic property is paramaterically related to a (superficially unrelated) syntactic property. The syntactic property has to do with proper names (PNs), which display cross-linguistic constant meaning but variable word order. In this way, the parameter is responsible for purely syntactic effects (word order) in one area of the grammar and purely semantic effects (presence or absence of an interpretation) in another area of the grammar.

Keeping in mind the language architecture that I have assumed in this article, this is still a mismatch at the syntax-semantics interface. The two meanings illustrated below, the kind reading and the distributive reading, are part of conceptual structure. The mismatch is at the level of how many meanings are possibly carried by BNs in a language. However, just looking at $\mathrm{BN}$ forms gives learners no indication of what meanings to attribute to them, since the form and the syntactic distribution of BNs are the same in Italian and English (they can be subjects and objects).

I illustrate the semantic difference with the contrast from anaphoric binding:

16) Large cats think very highly of themselves.

Distributive/Kind

17) Gatti di grossa taglia hanno un'alta opinione di se stessi. DisTRIBUTIVE/\#KIND cats of large dimensions have a high opinion of self

'Large cats think very highly of themselves.'

The distributive reading of (16) says that each individual large cat has a high opinion of itself only, although they may not think highly of the species in general. The kind reading of the same sentence is that every large cat has a high opinion of all large cats as a species, although they may not have a high opinion of individuals within the species, including their personal selves. The distributive reading is available in Italian, but the kind reading is not.

The word order contrast parametrically related to the semantic contrast above is exemplified with proper names modified by adjectives. In English, such names follow the adjective (18), while in Italian the names can precede the adjective as in (19):

18) Ancient Rome/*Rome ancient was destroyed by the barbarians.

19) Roma antica/*Antica Roma fu distrutta dai barbari.

Rome ancient/ancient Rome was destroyed by barbarians

'Ancient Rome was destroyed by the barbarians.' 


\section{Is there a critical period for semantics?}

Seventy-six Italian learners of English and 24 native English controls took a written Truth Value Judgement Task and a Grammaticality Judgement task. An independent measure of proficiency, a cloze test, was also administered. The TVJT (Crain and McKee, 1985) consisted of pairs of stories and test sentences. Each test sentence appeared twice, once under a story supporting a distributive interpretation of the nominal (some large cats) and a second time under a story supporting a kind interpretation (all large cats). ${ }^{11}$

20) Example of a story-sentence pair in the Anaphoric Binding Condition:

Distributive reading story:

Cats are strange animals. The large ones think that they are smart and handsome. At the same time, they consider all other large cats to be very ugly. Is this because they feel threatened by the members of their own species? I wonder ...

Large cats have a very high opinion of themselves. True False

Kind reading story:

I don't like small cats, but I adore large ones. The thing I like most about them is this: they think that every large cat in the world is smart and handsome. They just like each other very much. What a happy group of animals!

Large cats have a very high opinion of themselves. True False

There were no statistical differences between the two learner groups and the controls in accuracy of performance in this condition. The distributive reading was slightly, but not significantly, preferred by all groups. It seems that expanding the interlanguage grammar with another interpretation is indeed possible; see Table 3.

High accuracy on the GJ task suggests that knowledge of the syntactic aspect of the Bare Noun/Proper Name parameter has also been acquired. There may be (at least) two reasons for this successful acquisition: the

Table 3 Accuracy of interpretation in Truth Value Judgement Task (percentage)

\begin{tabular}{lcc}
\hline Groups & \multicolumn{2}{c}{ Anaphoric Binding } \\
\cline { 2 - 3 } & $\begin{array}{c}\text { Kind } \\
\text { reading }\end{array}$ & $\begin{array}{c}\text { Distributive } \\
\text { reading }\end{array}$ \\
\hline English natives $(n=24)$ & 80 & 88 \\
Advanced $(n=40)$ & 83 & 93 \\
High intermediate $(n=36)$ & 83 & 85 \\
\hline
\end{tabular}

\footnotetext{
${ }^{11}$ There was another condition testing a second semantic contrast in the study: The Bare Noun Interpretation Condition. I omit examples of it here for lack of space. However, the two conditions rely on the same underlying representations. The interested reader is directed to the original publication.
} 
interpretation missing in the native language is available in the L2 input, although it is not explicitly taught; there is also syntactic evidence parametrically related to it. The learners' success may be due to either reason, or indeed to a combination of the two.

\section{Other studies, very briefly}

The studies I have summarized in the previous sections are by no means the only ones that lead to the same conclusions. They are representative of a larger and growing body of work on the syntax-semantics interface. In Table 4, I represent, necessarily very schematically, 12 recent studies investigating semantic properties. All of the studies look at interpretations calculated at the syntax-semantics interface, whose acquisition presents a poverty of the stimulus or which are not taught overtly in language classrooms.

Do any tendencies emerge from these representative studies? I believe that, taken together with the three studies which I illustrated in more detail, some commonalities emerge. In the case of the Dekydtspotter, Sprouse and colleagues studies as well as Unsworth (2005), the properties under discussion involve quite complex syntax, in the sense that sentences involve less frequent constructions (double genitives, discontinuous constituents, scrambling). Very often the native speakers in these experiments show far less than the acceptance rates we are used to seeing in the L2 literature. However, at the syntax-semantics interface, these same properties do not present much difficulty, as there are no mismatches. If learners have constructed the right sentence representation, the presence or absence of semantic interpretation follows. In all cases, learners demonstrate that a contrast exists in their grammar between the allowed and the disallowed interpretation.

In Montrul and Slabakova (2002; 2003) and in Slabakova (2001; 2003), the syntax presents less difficulty to the learners. Not surprisingly, native speakers in these experiments show the regular range of accuracy (80-90\%). The learning challenges lie, however, at the syntaxsemantics interface. Learners have to figure out what forms are mapped on to what meanings in the target language, since there is no one-to-one correspondence at the syntax-semantics. When we consider results at 


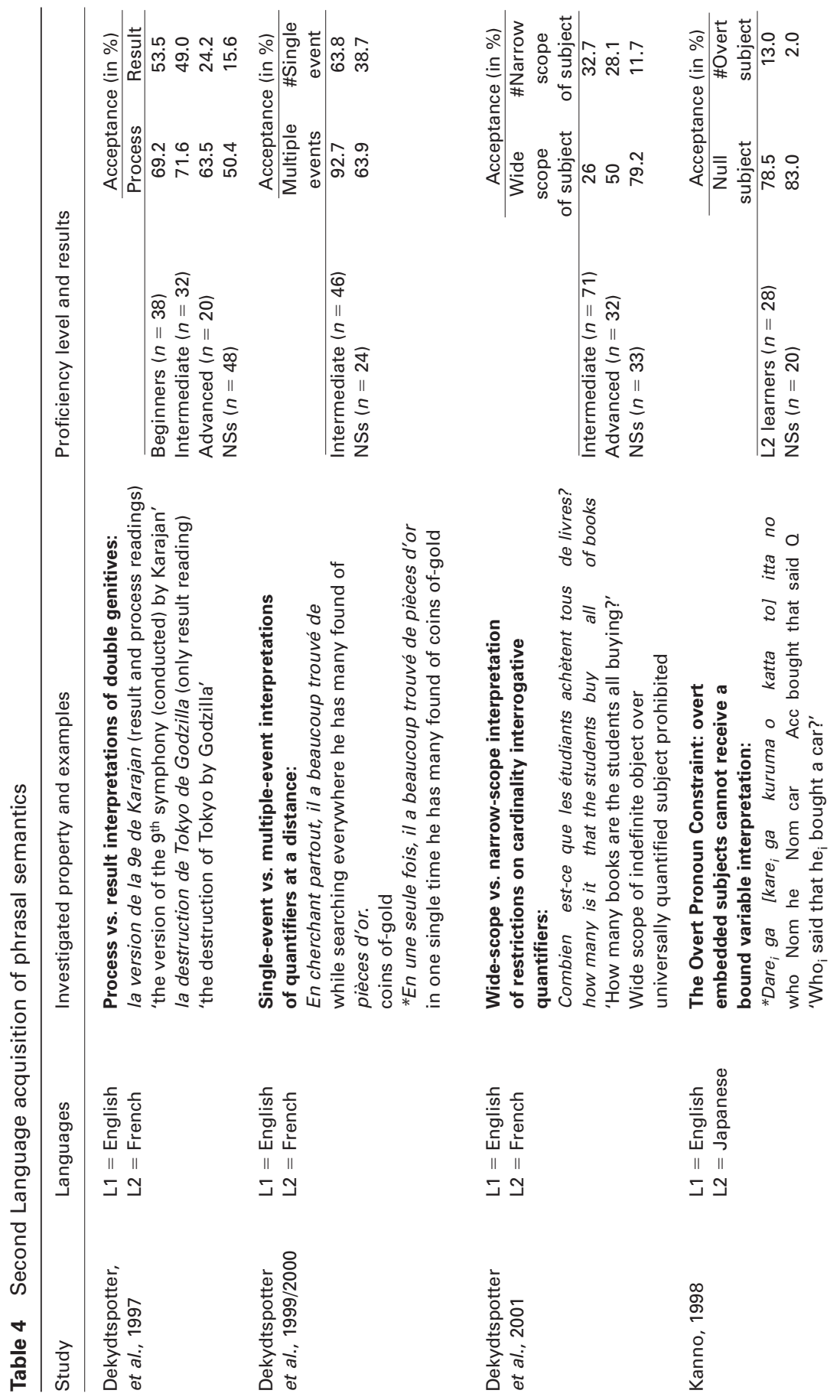




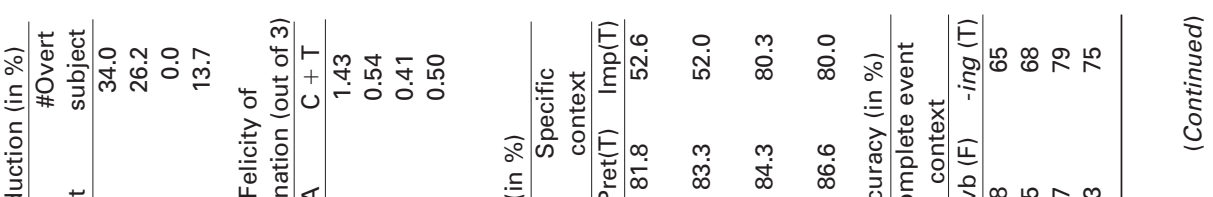

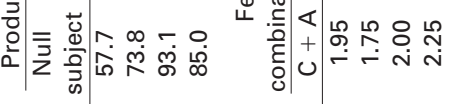
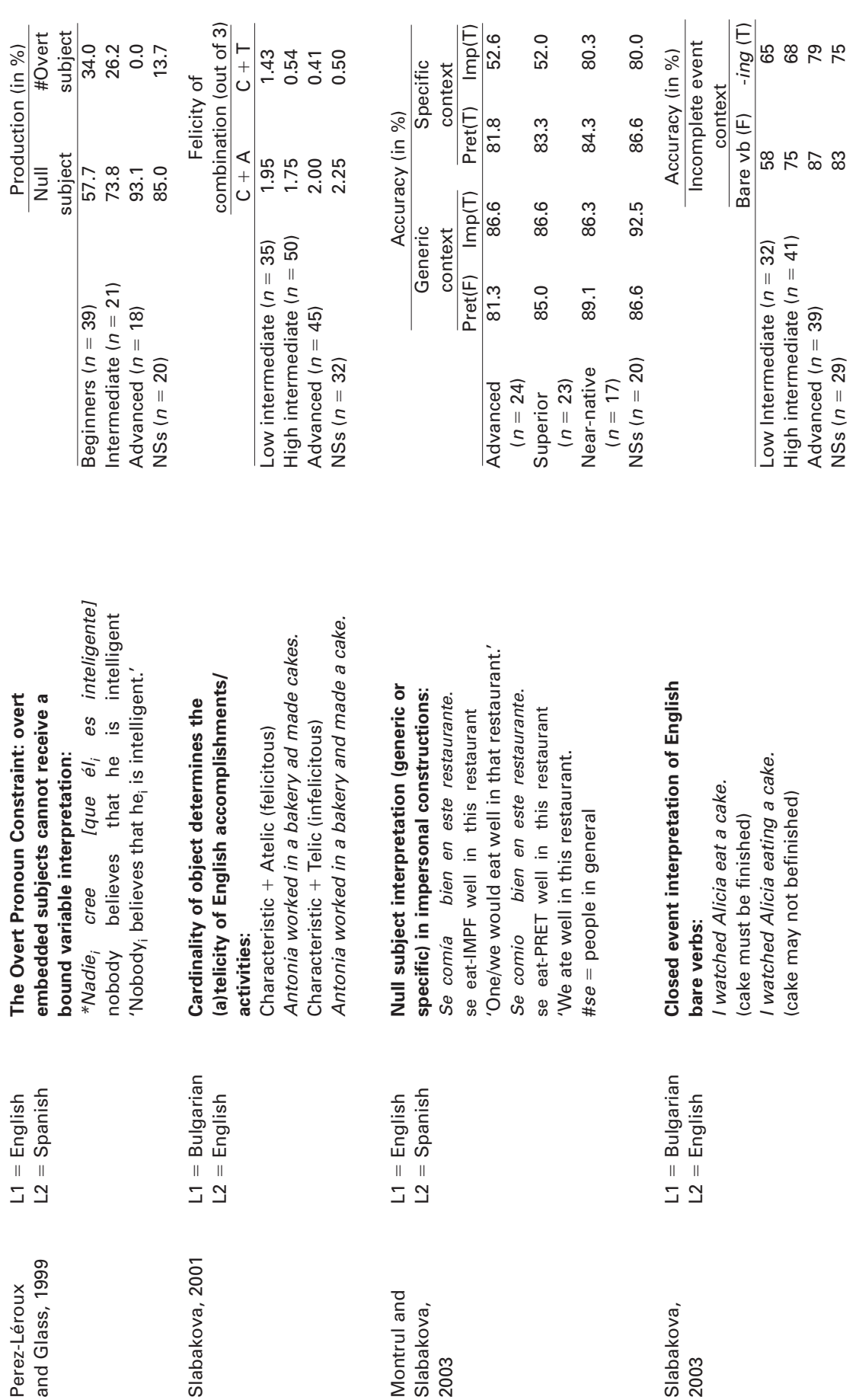

5
8
0
$\frac{0}{0}$
$\frac{1}{\pi}$
$\frac{0}{\pi}$
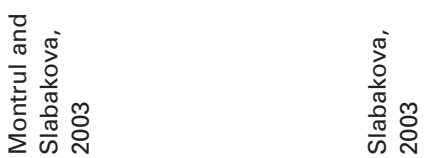


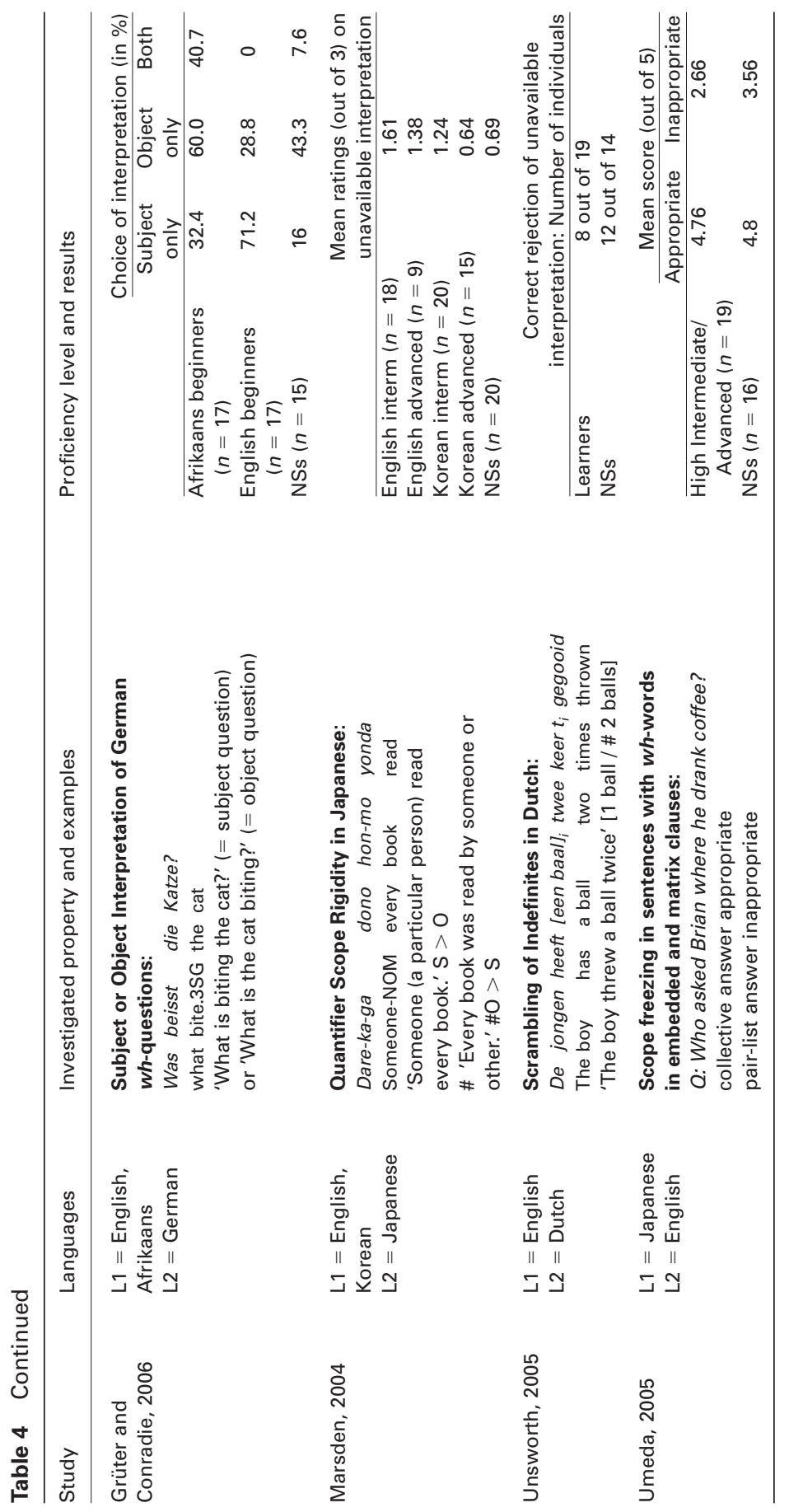


all levels of proficiency from beginner to near-native, it is clear that knowledge of these properties emerges gradually but surely.

\section{Conclusions}

Coming back to the question posed in the title of this article - is there a Critical Period for semantics - I would like to submit that the answer is No. First of all, this question makes sense only in the context of a specific linguistic theory that has a lucid notion of what semantics is and where it resides in the architecture of the language faculty. Jackendoff (2002) offers a clear and convincing picture of this architecture. He distinguishes between lexical semantics and phrasal semantics, and places the latter at the interface between syntactic structure and conceptual structure.

Recent advances in the neurolinguistics and psycholinguistics of bilingualism suggest that the $\mathrm{CPH}$ should be reconsidered: different neural pathways subsume the different linguistic modules (phonology, syntax, semantics) and there is some evidence that they can be differentially affected by AoA of the second language. When learners at different AoA are scanned, a lower AoA (around 3 years of age) brings qualitative difference in the processing of syntax while a much higher AoA (over 16) produces such difference in the processing of semantics. Proficiency is the most important factor determining whether L2 learners process the semantics like native speakers.

I also argued that studies comparing bilingual syntax and semantics often use test items that are linguistically unsophisticated and do not incorporate current linguistic-theoretical assumptions. In addition, neuroimaging and electrophysiological studies often jump to conclusions about activated brain areas, without having established through psycholinguistic means what cognitive processes are triggered by the experimental tasks and stimuli. In waiting for more conclusive semantic processing studies, we turn to behavioural investigations of how semantic properties are acquired by second language learners.

I have argued that the existing studies investigate learning situations of two types. D\&S (2001) illustrates one learning situation, where movement of a constituent in one construction (the continuous whphrase) but not in another (the discontinuous wh-phrase) creates scope 
effects reflected in the presence or absence of present-time interpretation. I argued that it may be the syntax that presents more difficulty to learners and native speakers, while the semantics is straightforward. In the other learning situation, illustrated in M\&S (2002), the challenge lies at the syntax-semantics interface: the same three meanings are mapped onto two different pieces of inflectional morphology . In both learning scenarios, adult learners demonstrate that they are perfectly capable of acquiring the properties under scrutiny. The Bottleneck Hypothesis suggested that functional morphology may be the source of L2 difficulties. However, there is no visible barrier to success in acquiring interpretation, or a cut-off age after which acquisition efforts will be futile. I am not aware of any study in the literature today that demonstrates failure on the part of adult learners to acquire phrasal semantic properties. Therefore, I believe that there is no critical period for semantics.

\section{Acknowledgements}

I gratefully acknowledge partial financial support by the Dean's Scholar Award, College of Arts and Sciences, the University or lowa. I would like to thank Donna Lardiere, the editor of this special issue, for inviting me to contribute, and two anonymous Second Language Research reviewers for helpful comments on an earlier version or this article. The remaining errors and weaknesses are mine alone.

\section{References}

Abutalebi, J., Cappa, S. and Perani, D. 2001: The bilingual brain as revealed by functional neuroimaging. Bilingualism: Language and Cognition 4, 179-90.

Ainswerth-Darnell, K., Shulman, H. and Boland, J. 1998: Dissociating brain responses to syntactic and semantic anomalies: evidence from event-related potentials. Journal of Memory and Language 38, 112-30.

Beck, M.L. 1998: L2 acquisition and obligatory head movement: Englishspeaking learners of German and the local impairment hypothesis. Studies in Second Language Acquisition 20, 311-48.

Binkofski, F., Amuts, K., Stephan, K.M., Posse, S., Schormann, T., Freund, H.-J., Zilles,K. and Seitz, R. 2000: Broca's region subserves 
imagery of motion: a combined cytoarchitectonic and fMRI study. Human Brain Mapping 11, 273-85.

Birdsong, D. 1992: Ultimate attainment in SLA. Language 68, 706-55.

Bley-Vroman, R. 1989: What is the logical problem of foreign language learning? In Gass, S. and Schachter, J., editors, Linguistic Perspectives on Second Language Acquisition. Cambridge University Press, 41-68.

Bobaljik, J. 2002: Realizing Germanic inflection: why morphology does not drive syntax. The Journal of Comparative Germanic Linguistics 6, 129-67.

Brown, C.M. and Hagoort, P. 1993: The processing nature of the N400: evidence from masked priming. Journal of Cognitive Neuroscience 5, 34-44.

Chee, M.W., Caplan, D., Soon, C.S., Sriram, N., Tan, E.W.L., Thiel, T. and Weekes, B. 1999: Processing of visually presented sentences in Mandarin and English studied with fMRI. Neuron 23, 123-37.

Chee, M.W., Hon, N., Lee, H.L. and Soon, C.S. 2001: Relative language proficiency modulates BOLD signal change when bilinguals perform semantic judgments. NeuroImage 13, 1155-63.

Chomsky, N. 2000: Minimalist inquiries: the framework. In Martin, R., Michaels, D. and Uriagereka, J., editors, Step by step: essays on minimalist syntax in honor of Howard Lasnik. MIT Press, 9-155.

_ 2001: Derivation by phase. In Kenstowitz, M., editor, Ken Hale: a Life in Language. MIT Press, 1-52.

- 2004: Beyond explanatory adequacy. In Belleti, A., editor, Structures and beyond: the cartography of syntactic structures. Volume 3. Oxford University Press, 104-31.

Clahsen, H., Penke, M. and Parodi, T. 1993/94: Functional categories in early child German. Language Acquisition 3, 395-429.

Coppieters, R. 1987: Competence differences between native and near-native speakers. Language 63, 544-73.

Crain, S. and McKee, C. 1985: The acquisition of structural restrictions on anaphora. Paper presented at the NELS 15, University of Massachusetts.

Dehaene, S., Dupoux, E., Mehler, J., Cohen, L., Paulesu, E., Perani, D., van Moortele, P.-F., Lehericy, S. and Le Bihan, D. 1997: Anatomical variability in the cortical representation of first and second language. NeuroReport 8, 3809-15.

Dekydtspotter, L. and Outcalt, S. 2005: A syntactic bias in scope ambiguity resolution in the processing of English-French cardinality interrogatives: evidence for informational encapsulation. Language Learning 55, $1-36$.

Dekydtspotter, L. and Sprouse, R.A. 2001: Mental design and (second) language epistemology: adjectival restrictions of $w h$-quantifiers and tense in English-French interlanguage. Second Language Research 17, 1-35. 
Dekydtspotter, L., Sprouse, R. and Anderson, B. 1997: The interpretive interface in L2 scquisition: the process - result distinction in English-French interlanguage grammars. Language Acquisition 6, 297-332.

Dekydtspotter, L., Sprouse, R. and Swanson, K. 2001: Reflexes of mental architecture in second language acquisition: the interpretation of discontinuous combien extractions in English-French interlanguage. Language Acquisition 9, 175-227.

Dekydtspotter, L., Sprouse, R. and Thyre, R. 1999/2000: The interpretation of quantification at a distance in English-French interlanguage: domainspecificity and second language acquisition. Language Acquisition 8, $265-320$.

Eubank, L. and Gregg, K. 1999: Critical periods and (second) language acquisition: divide et impera. In Birdsong, D., editor, Second language acquisition and the critical period hypothesis. Lawrence Erlbaum, 65-100.

Friederici, A.D. 1995: The time course of syntactic activation during language processing: a model based on neuropsychological and neurophysiological data. Brain and Language 50, 259-81.

2002: Towards a neural basis of auditory sentence processing. Trends in Cognitive Sciences 6, 78-84.

Friederici, A.D., Hahne, A. and Mecklinger, A. 1996: Temporal structure of syntactic parsing: early and late event-related brain potential effects. Journal of Experimental Psychology: Learning, Memory, and Cognition 22, 1219-48.

Friederici, A.D., Steinhauer, K. and Pfeifer, E. 2002: Brain signatures of artificial language processing: evidence challenging the critical period hypothesis. Proceedings of the National Academy of Science 99, 529-34.

Grüter, T. and Conradie, S. 2006: Investigating the L2 initial state: additional evidence from the production and comprehension of Afrikaans-speaking learners of German. In Slabakova, R., Montrul, S. and Prévost, P., editors, Inquiries in linguistic development: studies in honor of Lydia White. John Benjamins, 89-114.

Hagoort, P. and Brown, C.M. 1994: Brain responses to lexical ambiguity resolution and parsing. In Clifton, C., Frazier, L. and Rayner, K., editors, Perspectives on sentence processing. Lawrence Erlbaum, 45-81.

Hagoort, P., Brown, C.M. and Groothusen, J. 1993: The syntactic positive shift (SPS) as an ERP measure of syntactic processing. Language and Cognitive Processes 8, 439-83.

Hagoort, P., Hald, L., Bastiaansen, M. and Petersson, K.M. 2004: Integration of word meaning and world knowledge in language comprehension. Science 304, 438-41.

Hahne, A. 2001: What's different in second language processing? Evidence from event-related brain potentials. Journal of Psycholinguistic Research 30, 251-66. 
Hahne, A. and Friederici, A. 2001: Processing a second language: late learners comprehension mechanisms as revealed by event-related potentials. Bilingualism: Language and Cognition 4, 123-41.

Hawkins, R. 2005: Revisiting Wh-movement: the availability of an uninterpretable [wh] feature in interlanguage grammars. In Dekydtspotter, L. et al., editors, Proceedings of the 7th Generative Approaches to Second Language Acquisition Conference (GASLA 2004). Cascadilla, 124-37.

Hawkins, R. and Chan, C. 1997: The partial availability of Universal Grammar in second language acquisition: the 'failed functional features hypothesis'. Second Language Research 13, 187-226.

Haznedar, B. 2001: The acquisition of the IP system in child L2 English. Studies in Second Language Acquisition 23, 1-39.

Haznedar, B. and Schwartz, B. 1997: Are there optional infinitives in child L2 acquisition? In Hughes, E., Hughes, M. and Greenhill, A., editors, Proceedings of the $21^{\text {st }}$ annual Boston University Conference on Language Development. Cascadilla Press, 257-68.

Henson, R. 2006: Forward inference using functional neuroimaging: dissociations versus associations. Trends in Cognitive Sciences 10, 64-69.

Illes, J., Francis, W., Desmond, J., Gabrieli, J., Glover, G., et al., 1999: Convergent cortical representation of semantic processing in bilinguals. Brain and Language 70, 347-63.

Ionin, T. and Wexler, K. 2002: Why is 'is' easier than '-s'?: acquisition of tense/agreement morphology by child second language learners of English. Second Language Research 18, 95-136.

Jackendoff, R. 1996: The proper treatment of measuring out, telicity, and possibly even quantification in English. Natural Language and Linguistic Theory 14, 305-54. 2002: Foundations of Language. Oxford University Press.

Johnson, J. and Newport, E. 1989: Critical period effects on universal properties of language: the status of subjacency in the acquisition of a second language. Cognition 39, 215-58.

Kaan, E. and Swaab, T. 2002: The brain circuitry of syntactic comprehension. Trends in Cognitive Sciences 6, 350-56.

Kaan, E., Harris, A., Gibson, E. and Holcomb, P. 2000: The P600 as an index of syntactic integration difficulty. Language and Cognitive Processes 15, 159-201.

Kanno, K. 1998: The stability of UG principles in second-language acquisition: evidence from Japanese. Linguistics 36, 1125-46.

Kim, K.H.S., Relkin, N.R., Lee, K.M. and Hirsch, J. 1997: Distinct cortical areas associated with native and second languages. Nature 388, 171-74.

Kluender, R. and Kutas, M. 1993: Subjacency as a processing phenomenon. Language and Cognitive Processes 8, 573-633.

Kutas, M. and Hilliard, S.A. 1980: Reading senseless sentences: brain potentials reflect semantic anomaly. Science 207, 203-05. 
Lardiere, D. 1998a: Case and tense in the 'fossilized' steady state. Second Language Research 14, 1-26.

— 1998b: Dissociating syntax from morphology in a divergent end-state grammar. Second Language Research 14, 359-75.

— 2000: Mapping features to forms in second language acquisition. In Archibald, J., editor, Second language acquisition and linguistic theory. Blackwell, 102-29.

— 2005: On morphological competence. In Dekydtspotter, L., et al., editors, Proceedings of the 7th Generative Approaches to Second Language Acquisition Conference (GASLA 2004). Cascadilla, 178-92.

Lee, D. and Schachter, J. 1997: Sensitive period effects in binding theory. Language Acquisition 6, 333-62.

Lenneberg, E. 1967: Biological foundations of language. Wiley.

Long, M. 1990: Maturational constraints on language development. Studies in Second Language Acquisition 12, 251-85.

Longobardi, G. 2001: How comparative is semantics? A unified parametric theory of bare nouns and proper names. Natural Language Semantics 9, 335-69.

Maess, B., Koelsch, S., Gunter, T.C. and Friederici, A. 2001: Musical syntax is processed in Broca's area: an MEG study. Nature Neuroscience 4, $540-45$.

Marsden, H. 2003: Inverse scope in L2 Japanese. Cascadilla Press, 496-507.

— 2004: L2 knowledge of quantifier scope in Korean and English learners of Japanese. In Cazzoli-Goeta, M., Mukai, M. and Van Espen, L., editors, Durham Working Papers in Linguistics. Volume 10. School of Linguistics and Language, University of Durham, 137-50.

May, R. 1985: Logical form: its structure and derivation. MIT Press.

McKinnon, R. and Osterhout, L. 1996: Constraints on movement phenomena in sentence processing: evidence from event-related brain potentials. Language and Cognitive Processes 11, 495-523.

Montrul, S. and Slabakova R. 2002: Acquiring morphosyntactic and semantic properties of preterite and imperfect tenses in L2 Spanish. In PerezLéroux, A.-T. and Liceras, J., editors, The acquisition of Spanish morphosyntax: the L1-L2 connection. Kluwer, 113-49.

_2003: Competence similarities between native and near-native speakers: an investigation of the preterite/imperfect contrast in Spanish. Studies in Second Language Acquisition 25, 351-98.

Müller, U. 2005: Electrophysiological correlates of second language processing. Second Language Research 21, 152-74.

Münte, T.F., Heinze, H.J. and Mangun, G.R. 1993: Dissociation of brain activity related to syntactic and semantic aspects of language. Journal of Cognitive Neuroscience 5, 335-44.

Osterhout, L. and Holcomb, P.J. 1992: Event-related brain potentials elicited by syntactic anomaly. Journal of Memory and Language 31, 785-806. 
Paradis, M. 1994: Neurolinguistic aspects of explicit and implicit memory: implications for bilingualism. In Ellis, N., editor, Implicit and explicit learning of second languages. Academic Press, 393-419.

- 2004: A neurolinguistic theory of bilingualism. John Benjamins.

Patkowski, M. 1980: The sensitive period for the acquisition of syntax in a second language. Language Learning 30, 449-72.

Penfield, W. and Roberts, L. 1959: Speech and brain mechanisms. Atheneum.

Perani, D., Paulesu, E., Sebastian-Galles, N., Dupoux, E., Dehaene, S., Bettinardi, V., Cappa, S., Fazio, F. and Mehler, J. 1998: The bilingual brain: proficiency and age of acquisition of the second language. Brain 121, 1841-52.

Perani, D., Dehaene, S., Grassi, F., Cohen, L., Cappa, S., Paulesu, E., Dupoux, E., Fazio, F. and Mehler, J. 1996: Brain processing of native and foreign languages. NeuroReport 7, 2439-44.

Pérez-Leroux, A.-T. and Glass, W. 1999: Null anaphora in Spanish second language acquisition: probabilistic versus generative approaches. Second Language Research 15, 220-49.

Poldrack, R. 2006: Can cognitive processes be inferred from neuroimaging data? Trends in Cognitive Sciences 10, 59-63.

Radford, A. 1990: Syntactic theory and the acquisition of English syntax. Blackwell.

Sabourin, L. 2003: Grammatical gender and second language processing: an ERP study. Unpublished doctoral dissertation, University of Groningen.

Samuels, R. 2000: Massively modular minds: evolutionary psychology and cognitive architecture. In Carruthers, P. and Chamberlain, A., editors, Evolution and the mind: modularity, language, and meta-cognition. Cambridge University Press, 13-46.

Schubotz, R.I. and von Crammon, D.Y. 2001: Interval and ordinal properties of sequences are associated with distinct premotor areas. Cerebral Cortex 11, 210-22.

Slabakova, R. 2001: Telicity in the Second Language. John Benjamins.

— 2003: Semantic evidence for functional categories in interlanguage grammars. Second Language Research 19, 42-75.

2006: Learnability in the L2 acquisition of semantics: a bidirectional study of a semantic parameter. Second Language Research.

Slabakova, R. and Montrul S. 2002: On viewpoint aspect and its L2 acquisition: a UG perspective. In. Salaberry, R. and Shirai, Y., editors, Tense-aspect morphology in L2 acquisition. John Benjamins, 363-98.

— 2003: Genericity and aspect in L2 acquisition. Language Acquisition 11, 165-96.

Sorace, A. 1993: Incomplete versus divergent representations of unaccusativity in non-native grammars of Italian and French. Second Language Research 9, 22-47. 
- 2000: Differential effects of attrition in the L1 syntax of near-native L2 speakers. In Howell, S.C., Fish, S.A. and Keith-Lucas, T., editors, Proceedings of the 24th Boston University Conference on Language Development. Cascadilla Press, 719-25.

- 2003: Near-nativeness. In Doughty, C. and Long, M., editors, The handbook of second language acquisition. Blackwell, 130-51.

Sprouse, R. 1998: Some notes on the relationship between inflectional morphology and parameter setting in first and second language acquisition. In Beck, M.-L., editor, Morphology and its interfaces in second language knowledge. John Benjamins, 41-67.

de Swart, H. 1998: Aspect shift and coercion. Natural Language and Linguistic Theory 16, 347-85.

Ullman, M. 2001: The neural basis of lexicon and grammar in first and second language: the declarative/procedural model. Bilingualism: Language and Cognition 4, 105-22.

2004: Contributions of memory circuits to language: the declarative/procedural model. Cognition 92, 231-70.

Umeda, M. 2005: Wh-movement in Japanese-English interlanguage: evidence from scope and reconstruction. In Brugos, A., Clark-Cotton, M.R. and Ha, S., editors, BUCLD 29 Proceedings. Cascadilla Press, 616-26.

Unsworth, S. 2005: Overcoming the poverty-of-the-stimulus: scrambled indefinites in English-Dutch interlanguage. In Brugos, A., Clark-Cotton, M.R. and Ha, S., editors, BUCLD 29 Proceedings. Cascadilla Press, 627-38.

Urbanik, A., Binder, M., Sobieska, B. and Kozub, J. 2001: fMRI study of sentence generation by early bilinguals differing in proficiency level. Rivista di Neuroradiologia 14, 11-16.

Vaid, J. and Hull, R. 2002: Re-envisioning the bilingual brain using functional neuroimaging: methodological and interpretive issues. In Fabbro, F., editor, Advances in the neurolinguistics of bilingualism. Forum-Undine University, 315-56.

Wartenburger, I., Heekeren, H.R., Abutalebi, J., Cappa, S., Villringer, A. and Perani, D. 2003: Early setting of grammatical processing in the bilingual brain. Neuron 37, 159-70.

Weber-Fox, C.M. and H, Neville. 1996: Maturational constraints on functional specializations for language processing: ERP and behavioral evidence in bilingual speakers. Journal of Cognitive Neuroscience 8, 231-56.

- 2001: Sensitive periods differentiate processing of open- and closedclass words: an ERP study of bilinguals. Journal of Speech, Language, and Hearing Research 44, 1338-53.

White, L. 2003: Second language acquisition and Universal Grammar. Cambridge University Press. 